\title{
Economic evaluation of animal disease control strategies: Application of a relational database system
}

Maria Näther ${ }^{1}$, Ludwig Theuvsen²

\begin{tabular}{|c|c|}
\hline I N F O & A B S T R A C T \\
\hline Received & \\
\hline Accepted & The outbreak of an animal disease such as swine fever can have far-reaching economic \\
\hline Available on-line & which affect not only livestock owners but also upstream and downstream \\
\hline Responsible Editor: & $\begin{array}{l}\text { industries and other stakeholders (such as veterinary agencies). Swine fever is the animal } \\
\text { disease with the most significant economic impact in the area of pig production }\end{array}$ \\
\hline Keywords: & worldwide. Until now it was almost impossible to calculate the macroeconomic impact \\
\hline Animal-Disease-Decision- & of a swine fever outbreak in European countries such as Germany. This paper uses the \\
\hline Support-System, & elational database management system TEUS to economically asses an animal disease \\
\hline Relational Database System, & outbreak by addressing the assumptions underlying the calculation. Five cost categories \\
\hline Entity-Relationship Model, & are proposed using parameters which influence the costs of an outbreak. Furthermore, \\
\hline Scenario Analysis. & $\begin{array}{l}\text { important basics of TEUS like the entity-relationship (ER)-model or the respective } \\
\text { algorithms of the programmed system are depicted. The programmed relational database } \\
\text { system TEUS can generate and calculate different scenarios, by varying parameters and } \\
\text { thereby generating a decision space. Furthermore, TEUS can also be used to analyse } \\
\text { economic aspects of other animal diseases or the outbreak of a disease in other countries. }\end{array}$ \\
\hline
\end{tabular}

\section{Introduction}

The outbreak of an animal disease such as swine fever can have far-reaching economic consequences which affect not only livestock owners but also upstream and downstream industries and other stakeholders (such as veterinary agencies). Swine fever is the animal disease exercising the most significant economic impact on worldwide pig production (Hirsch 2010; Moennig 2000). The direct costs caused by the latest outbreak of the classical swine fever (CSF) in Germany in 2006, for instance, were estimated at approximately $€$ 40-80 million (Jaeger 2006). According to Meuwissen et al. (1999), the total costs of the latest Dutch CSF outbreak (1997/1998) were around 2.3 billion Euros and 11 million pigs were culled. Currently, there is increasing danger of a new disease outbreak in various European countries as the African swine fever (ASF) has already reached the EU member states Poland and Lithuania (Blome and Beer 2013). As a consequence, the export of pork is already severely restricted since Russia almost completely has stopped its entire importation of pork from the EU (LWW-L 2014). Besides the losses on the export markets, the outbreak of an animal disease also leads to economic and non-financial (for instance, image-related) damage on domestic markets. Thus, animal disease control presents a great challenge, for solutions not only must integrate epidemiological or social aspects but also economic principles.

In 2013 an initial study sought to assess the macroeconomic impact of a CSF outbreak under application of alternative animal disease control strategies (Näther et al. 2013). For this purpose 24 scenarios were devised with Excel, which differed in regards to the assumptions made on regional livestock density, number of disease outbreaks, geographic location and distance of time of subsequent outbreaks. Näther et al. (2013) investigated the impact of the control strategies "culling" and "observing" on the economic consequences of a CSF outbreak. Due to the need for the introduction of additional

\footnotetext{
1 Maria Näther

Department of Agricultural Economics and Rural Development, Georg-August-University Göttingen, Germany maria.naether@agr.uni-goettingen.de

${ }^{2}$ Ludwig Theuvsen

Department of Agricultural Economics and Rural Development, Georg-August-University Göttingen, Germany Theuvsen@uni-goettingen.de
}

doi: $10.17700 /$ iai.2015.6.4.211

Maria Näther, Ludwig Theuvsen: Economic evaluation of animal disease control strategies: Application of a relational database system 
parameters, e.g. the control strategy "vaccination", and cost validation, the authors decided to create a user-friendly IT-based instrument to calculate the economic consequences of a CSF outbreak. The goal of this paper is to present a newly developed animal disease decision support system called TEUS (in

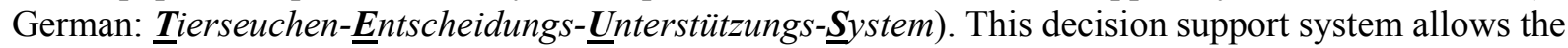
economic evaluation of possible consequences of a swine fever outbreak and the subsequent application of alternative disease control strategies. This helps to show to what extent and in which parts of the value chain economic losses are caused by the outbreak of swine fever. The programmed relational database system TEUS can generate and analyse a large set of different scenarios in order to determine the economic impact of a new swine fever outbreak under various assumptions and the use of alternative strategies to combat animal diseases.

The remainder of the paper is organized as follows: The second section describes the basis of the subsequent calculations, i.e. the basic assumptions, the relevant cost categories and the parameters which have influence on the costs. Section 3 illustrates the basics of the animal disease decision support system by describing the entity-relationship (ER) model, the algorithms used in the system and the masks presentation. The final section 4 presents concluding remarks on this study.

\section{Basis of Calculation}

\subsection{Basic Assumptions}

TEUS and, thus, the cost calculations are based on two basic assumptions. First, TEUS assumes circular protection and surveillance zones established in accordance with Council Directive 2001/89/EC after the outbreak of a disease. Second, it is assumed that an outbreak of a disease can be assigned to one of two following possible scenario types: either it is a classical, singular outbreak (Scenario-Type 1), or there are two outbreaks characterized by temporal and geographical distance between the first and the second outbreak (Scenario-Type 2). In the second case it is possible to differentiate between (a) overlapping protection and/or surveillance zones and (b) completely distinct protection and surveillance zones (Figure 1). The latter means that there are additional economic consequences, for instance, due to the need to establish a second disease control strategy and infrastructure.

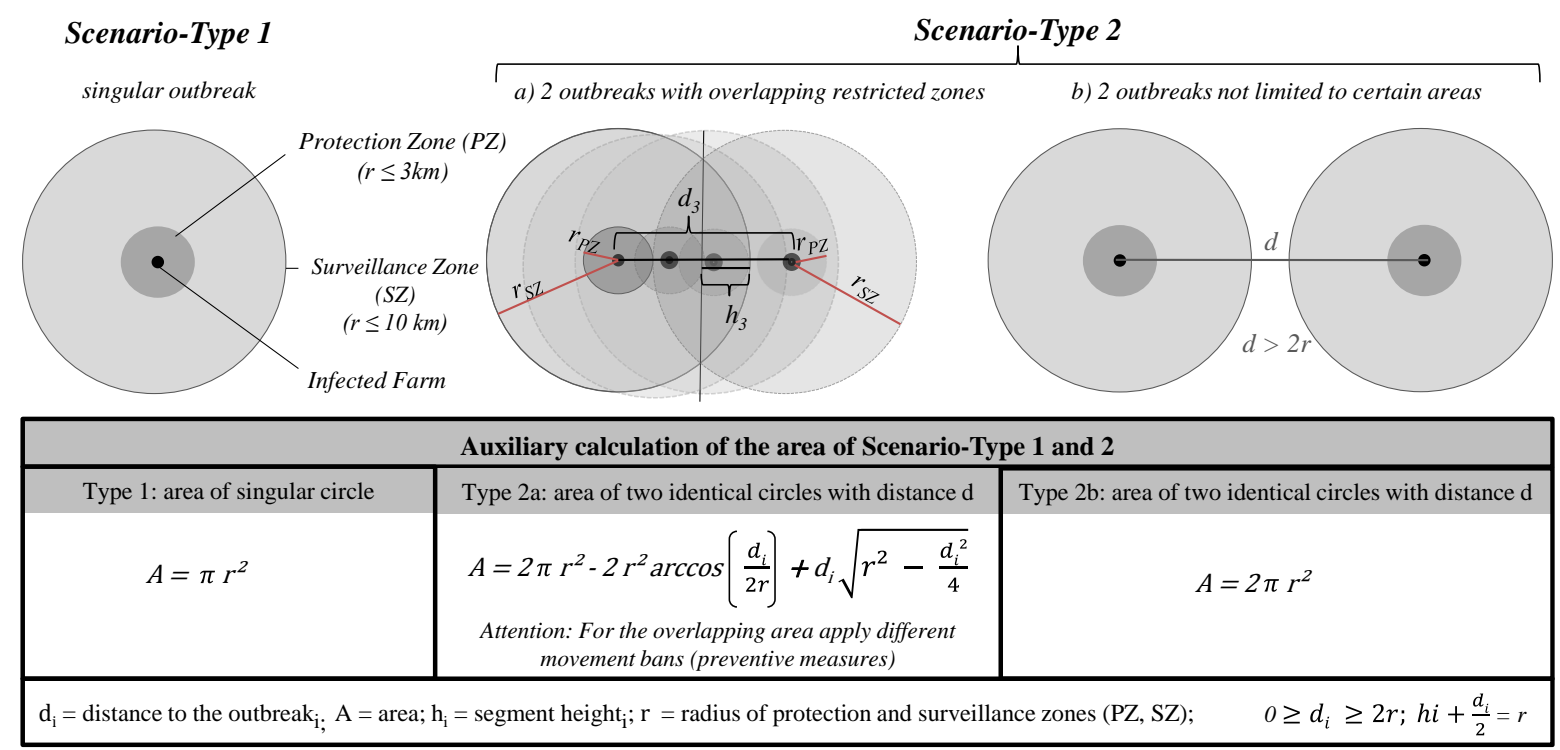

Figure 1. The Scenario-Types 1 and 2

\subsection{The Cost Categories}

The study considers five cost categories to calculate the total economic damage of a swine fever outbreak. These cost categories embrace 22 cost sub-categories and 61 different types of costs, which 
were validated through an extensive literature review and expert interviews (Table 1). However, the cost sub-categories „1.6 Vaccination costs“ and „2.7 Non-reimbursed vaccination costs“ (italics) play a decisive role only for the CSF, because there is currently no vaccine available for the ASF virus (Blome 2014; SUS 2014).

Table 1. Cost Categories with validated Types of Costs for a Classical Swine Fever Outbreak (based on Näther et al. 2013)

\begin{tabular}{|c|c|c|c|c|}
\hline Cost Categories & Sub-Cost Categories & Types of Costs & $€$ & Unit \\
\hline \multirow{22}{*}{$\begin{array}{l}\text { CC 1: Costs of } \\
\text { governmental control }\end{array}$} & \multirow{4}{*}{ 1.1 Compensation through Animal Disease Fund } & Per Boar & 535.5 & per animal \\
\hline & & Per Piglet & 75.5 & per animal \\
\hline & & Per Hog & 114.8 & per animal \\
\hline & & Per Sow & 459.0 & per animal \\
\hline & \multirow{7}{*}{ 1.2 Government aid for part-financing } & Cost of slaughtering per Piglet & 5.0 & per animal \\
\hline & & Cost of slaughtering per Hog & 5.0 & per animal \\
\hline & & Cost of slaughtering per breeder & 10.0 & per animal \\
\hline & & Cleansing \& Disinfection Measures Piglet & 0.8 & per animal \\
\hline & & Cleansing \& Disinfection Measures Hog & 3.3 & per animal \\
\hline & & Cleansing \& Disinfection Measures Breeder & 7.5 & per animal \\
\hline & & Rendering of carcasses & 135.0 & ton \\
\hline & \multirow{3}{*}{ 1.3 Other assistance } & Herd test per animal & 4.2 & per animal \\
\hline & & \begin{tabular}{|l|} 
Diagnostics per animal \\
\end{tabular} & 7.0 & per animal \\
\hline & & Preventive part-financing per animal & 18.0 & per animal \\
\hline & \multirow{3}{*}{ 1.4 Labour costs } & Labour for culling & 2.0 & per animal \\
\hline & & Fire brigade/THW (technical assistance organisation) & 11600.0 & once \\
\hline & & Other Labour costs & 1.4 & per animal \\
\hline & 1.5 Cost of material & Cost of Material & 4.4 & per animal \\
\hline & \multirow{4}{*}{ 1.6 Vaccination costs(just for CSF) } & vaccine dose/animal & 1.0 & per animal \\
\hline & & Cost of Material for vaccine & 12.0 & per test and animal \\
\hline & & Labour costs vaccine & 0.3 & per animal \\
\hline & & Other costs & 0.5 & per animal \\
\hline \multirow{23}{*}{$\begin{array}{l}\text { CC 2: Costs of farms } \\
\text { directly affected } \\
\text { (infected/culled) }\end{array}$} & \multirow{4}{*}{ 2.1 Value of culled animals (not compensated) } & Per Boar & 59.5 & $10 \%$ \\
\hline & & \begin{tabular}{|l|} 
Per Piglet \\
\end{tabular} & 8.4 & $10 \%$ \\
\hline & & Per Hoag & 12.8 & $10 \%$ \\
\hline & & Per Sow & 51.0 & $10 \%$ \\
\hline & \multirow{4}{*}{ 2.2 Loss of production because of vacancy } & Per Boar/ day & 0.0 & per animal and day \\
\hline & & \begin{tabular}{|l|} 
Per Piglet/ day \\
\end{tabular} & 0.1 & per animal and day \\
\hline & & Per Hoag/ day & 0.2 & per animal and day \\
\hline & & Per Sow/ day & 1.5 & per animal and day \\
\hline & \multirow{3}{*}{ 2.3 Additional cleansing \& disinfection measures } & Per Sow or Breeder & 40.0 & per space \\
\hline & & Per Fattening Space & 1.7 & per space \\
\hline & & Per Piglet Space & 4.3 & per space \\
\hline & \multirow{3}{*}{ 2.4 Disposal of stocked fodder } & Per Sow or Breeder & 88.8 & per space \\
\hline & & \begin{tabular}{|l|} 
Per Piglet Space \\
\end{tabular} & 23.85 & per space \\
\hline & & Per Fattening Space & 44.67 & per space \\
\hline & \multirow{3}{*}{ 2.5 Additional deterioration because of stagnation } & Per Sow or Breeder & 9.1 & per space \\
\hline & & \begin{tabular}{|l|} 
Per Fattening Space \\
\end{tabular} & 1.0 & per space \\
\hline & & Per Piglet Space & 0.4 & per space \\
\hline & \multirow{3}{*}{ 2.6 Reduced performance in case of restocking } & Per Sow or Breeder & 310.0 & per animal \\
\hline & & \begin{tabular}{|l|} 
Per Piglet Space \\
\end{tabular} & 33.2 & per animal \\
\hline & & Per Fattening Space & 42052.0 & per animal \\
\hline & \multirow{3}{*}{ 2.7 Not reimbursed vaccination costs } & Laour costs of vaccination per hog & 0.0 & per animal \\
\hline & & vaccine dose/animal & 0.0 & per animal \\
\hline & & $\begin{array}{l}\begin{array}{l}\text { Less income because of vaccine per animal to be } \\
\text { slaughtered }(1.27 € / \mathrm{kg} \mathrm{SG})\end{array} \\
\end{array}$ & 124.5 & $90 \%$ \\
\hline \multirow{4}{*}{$\begin{array}{l}\text { CC 3: Costs of farms } \\
\text { indirectly affected (not } \\
\text { culled, but in the } \\
\text { restriction zone) } \\
\end{array}$} & 3.1 Costs of sub-optimal weights & Hog & 1.3 & per animal and day \\
\hline & 3.2 Loss of production because of marketing & $\operatorname{Hog}(0.21 * 0.87)$ & 0.2 & per animal and day \\
\hline & 3.3 Increased loss of swine & Hog $(138.18 * 0.0158) / 28$ & 0.1 & per animal and day \\
\hline & 3.4 Extraordinary veterinary expenses & Hog $(0.19 / 28)$ & 0.1 & per animal and day \\
\hline \multirow{6}{*}{$\begin{array}{l}\text { CC 4: Other costs in } \\
\text { agribusiness }\end{array}$} & \multirow{3}{*}{ 4.1 Sales decline in the feed industry } & Per Piglet/day & 0.2 & per day \\
\hline & & Per Hog/day & 0.6 & per day \\
\hline & & Per Sow or breeder/day & 1.0 & per day \\
\hline & 4.2 Price drop for swine & Less income (35 Cent/kg SG) per day & 5489269.1 & per day \\
\hline & \multirow{2}{*}{ 4.3 Reduced consumption of domestic pork } & Short term reduction of consumption $3 \%$ per day & 590314.5 & per day \\
\hline & & Longterm reduction of consumption $\%$ per day & 0.0 & per day \\
\hline CC 5: Effects on foreign & 5.1 Reduction of intra-community shipments & Less Shipments to EU x\% per day & 1877537.0 & per day \\
\hline trade & 5.2 Breaking off of export markets & Loss of Exports third countries (all) per day & 1308766.3 & per day \\
\hline
\end{tabular}

On the basis of these types of costs and with the help of special algorithms implemented into TEUS, it is possible to calculate values for the alternative scenarios which take into account the variation of various cost-relevant parameters. Furthermore, in this study indirect costs, e.g. negative effects on the tourism business, are disregarded, as thus far such effects have only been observed in the case of major Foot-and-Mouth Disease and bird flu outbreaks (Bidder 2006; Deblitz 2001).

doi: $10.17700 /$ jai.2015.6.4.211

Maria Näther, Ludwig Theuvsen: Economic evaluation of animal disease control strategies: Application of a relational database system 


\subsection{The Cost Determinants}

On the left side of Figure 2 are the parameters, which influence the economic effects of an epidemic event and can be varied in TEUS. The "percentage distribution" refers to the relevant category of animal. According to the Federal Statistical Office Census, Germany's pig stock consisted of $69 \%$ hogs, $24 \%$ piglets, $7 \%$ sows and $0.1 \%$ boars in 2010 (Statistisches Bundesamt 2011). These numbers are assumed in this study. The livestock density, i.e. the number of pigs, varies in Germany between 0 and 1,300 animals/ $\mathrm{km}^{2}$ in the district of Cloppenburg, which is the district with the highest density (Dieckhoff 2014). Further cost-relevant parameters are the distance and the time period between two subsequent outbreaks. When considering distance, it is especially important to consider the size of the protection and surveillance zones and the resulting overlapping area or the physical distance (cf. scenario-types $2 \mathrm{a}$ and $2 b)$. In the case of two outbreaks with overlapping surveillance zones $(d \leq 2 r$; scenario-type $2 a)$ the time periods of movement bans for pigs differ between overlapping and non-overlapping areas. In the latter, the usual restrictions need to be considered, but in the overlapping areas the movement bans of all of the outbreaks apply. Therefore, the time period between the outbreaks is a further important parameter which affects especially the cost categories 3 to 5 .

The parameters of the protection and surveillance zones and the control strategies are also relevant parameters. As soon as a swine fever incidence is confirmed, a protection zone $(\mathrm{r} \geq 3 \mathrm{~km})$ and a surveillance zone $(r \geq 10 \mathrm{~km})$ are established around the infected farm in order to isolate the pathogen according to the relevant Art. 9 of Directive 2001/89/EC. Different movement bans apply to the livestock owners in the protection and surveillance zones. In the case of a CSF outbreak, the movement bans in the protection zone apply for $\geq 28$ days, in the surveillance areas for $\geq 21$ days, whereas in the case of the ASF in the protection zone for $\geq 40$ days and in the surveillance areas for $\geq 30$ days. Furthermore, based on experience from European neighbouring countries, experts assume that in the case of an ASF outbreak, enlarged protection and surveillance zones (e.g. protection zone: $r \geq 4 \mathrm{~km}$; surveillance zone: $r \geq 15 \mathrm{~km}$ ) will be established (Groeneveld 2014). Within the protection zone, at the very minimum, the infected animal population is culled. However, in practice, an initial pre-emptive culling zone is established within a radius of $0.5-1 \mathrm{~km}$ around the infected holding. This is usually done because it is possible that the pathogen is already spread due to weather conditions or movements of animals, humans, machines etc. (Hop et al. in print). As a result, a survey of all pig stocks is done, conducting inspections and investigations of these stocks in the protection and surveillance zones and introducing stricter hygiene regulations (Council Directive 2001/89/EC). Control strategies may include culling, monitoring and vaccination of pig stocks. In the past culling and monitoring were dominant strategies applied in case of a disease outbreak. However, because of growing animal welfare concerns, there has to be an alternative to culling. For example, the emergency vaccination for CSF using the new DIVA-vaccine (Differentiating Infected from Vaccinated Animals) (EMA 2014) and the pathological distinction between infected and vaccinated animals through automatable real time PCR (Polymerase chain reaction) can be part of the answer (Moennig 2000). In an emergency vaccination, animals within a certain area around the infected farm are vaccinated. This vaccination zone can extend from the infected holding to cover the entire monitored area (Thulke 2014). Many international studies (Backer et al. 2009; Boklund et al. 2009; Brosig et al. 2012; Dürr et al. 2013; Ribbens et al. 2012) have evaluated the effectiveness of emergency vaccination. Research has shown that a $2-3 \mathrm{~km}$ large vaccination zone has the same epidemiological effectiveness as a $1 \mathrm{~km}$ large pre-emptively culling zone.

TEUS is able to take into account variations of the following parameters: regional livestock density, number and geographical distance of subsequent outbreaks, size of the protection and surveillance zones, control strategies implemented (culling, observing or vaccinating), time between outbreaks and the length of time periods characterized by decreasing pig meat consumption, pig prices, reduced exports, etc. The parameters are incorporated into the TEUS model with the help of algorithms which allow modelling the consequences of an outbreak and the implementation of alternative animal disease control strategies. 


\section{The Animal Disease Decision Support System}

The database management system TEUS was developed to show the macroeconomic impact of ASF and CSF and to extend the pilot study (Näther et al. 2013) with additional assumptions and parameters. The analysis of the pilot study shows that the increased number of scenarios, inclusion of ASF, consideration of the strategy "vaccination" in case of CSF and adding new algorithms make the usage of an excel-based calculation nearly impossible, especially when considering the need to potentially perform a sensitivity analysis. Consequently, a new instrument had to be developed which fulfilled these requirements. TEUS therefore was constructed using the development environment Gupta TeamDeveloper (version 6.2) and the relational database management system SQLBase (version 11.7). The programming language 4GL (source code) was used for the graphic interface and the embedded SQLqueries was SQLWindows.

\subsection{The ER-Model}

The ER-model is the architecture of a relational database system and connects the above-mentioned points, in which the entities (cost categories, parameters, algorithms, etc.) and the respective relations between the entities are listed. The specifications of the ER-model were defined by a pilot study (Näther et al. 2013). Figure 2 illustrates a simplified ER-model of TEUS.

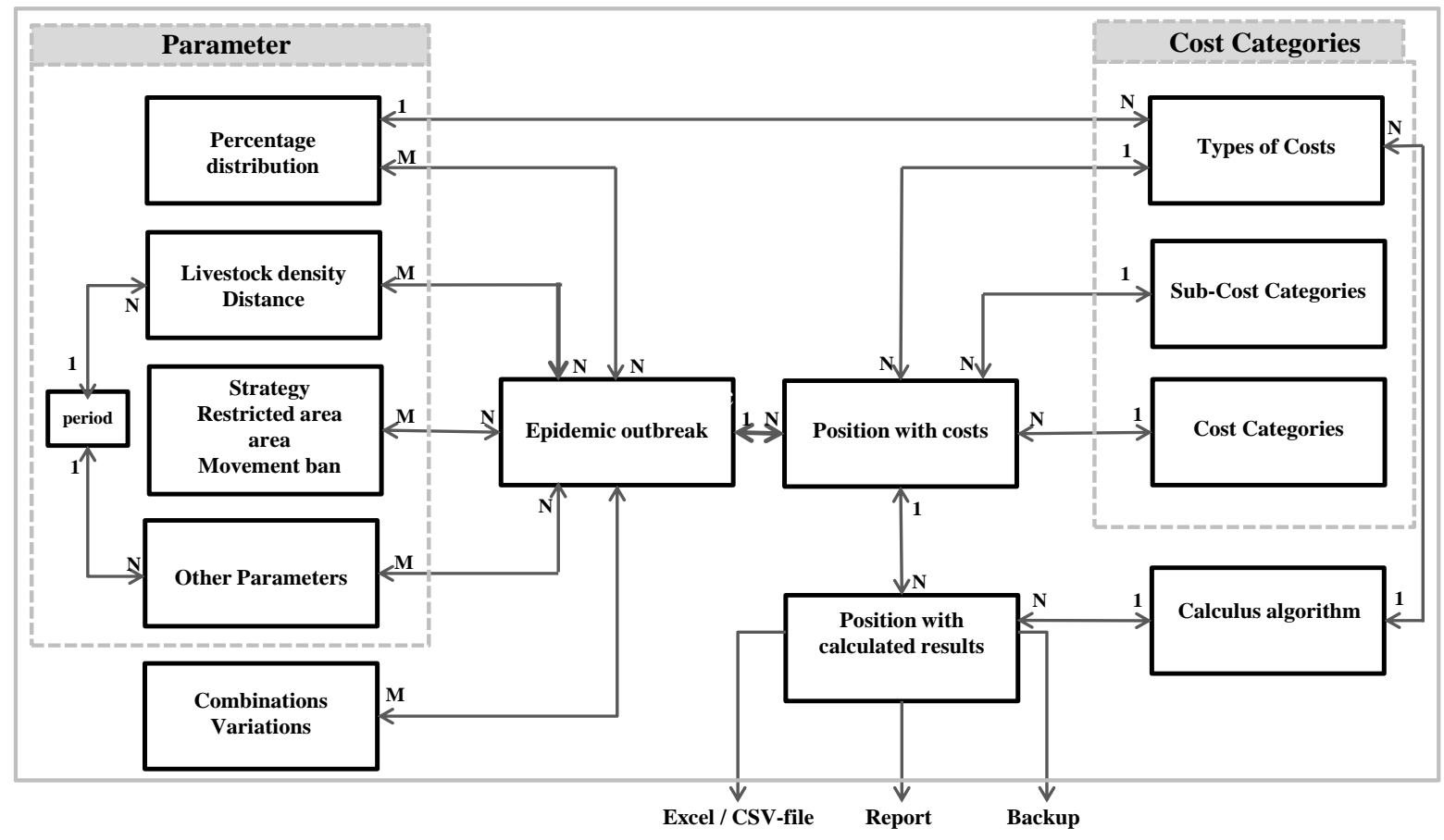

Figure 2. The simplified ER-model

It is important to point out two different groups of entities: the cost categories with the respective sub-cost categories and types of cost and the parameters such as animal density, time and distance between outbreaks, protection and surveillance zones, radii, and strategies. The arrows depict the relationships between the entities of the ER-model with the cardinality $1, \mathrm{~N}$ or $\mathrm{M}$. A classic 1 to $\mathrm{N}$ relationship as between "percentage distribution" and "type of cost" implies that one type of cost can be assigned to exactly one "percentage distribution" and one "percentage distribution" can be used in many (N) types of cost. In the case of $\mathrm{M}$ to $\mathrm{N}$ relationships on both sides, various objects exist in the entity. With the help of this ER-model, the respective input masks and the necessary functionalities were programmed to save the calculated results as a backup, get a printable report, and be able to export results into a CSV file as a basis for further calculation and analysis. 


\subsection{The Algorithms}

With the help of TEUS it is possible to analyse and evaluate a large number of scenarios, by varying parameters and thereby generating a decision-making arena. It is also possible to introduce new types of cost (compared to the pilot study) and the respective algorithms of the programmed system TEUS. In the following we present the algorithms to determine the results of a type of cost:

- value * 1 (one-off costs)

- $\quad$ value * assigned number of days

- $\quad$ number of animals $=$ livestock density $*$ net square footage $*$ percentage distribution

- $\quad$ value * number of animals

- $\quad$ value * number of animals * period $\mathrm{N}$ in days (movement ban)

- $\quad$ value * period $\mathrm{N}$ in days (movement ban) according to the Gaussian algorithms:

$$
\mathrm{G}(\mathrm{N})=\frac{N *(N+1)}{2} \text { and }
$$

- $\quad$ value * tons (converted target weight of number of animals).

\subsection{The System Masks Presentation}

The three most important masks are presented: Figure 3 describes the cost categories with its subcategories and types of costs and value. This figure represents the cost category 4: Other Costs in Agribusiness (cf. section 2.2) and its auxiliary calculation.

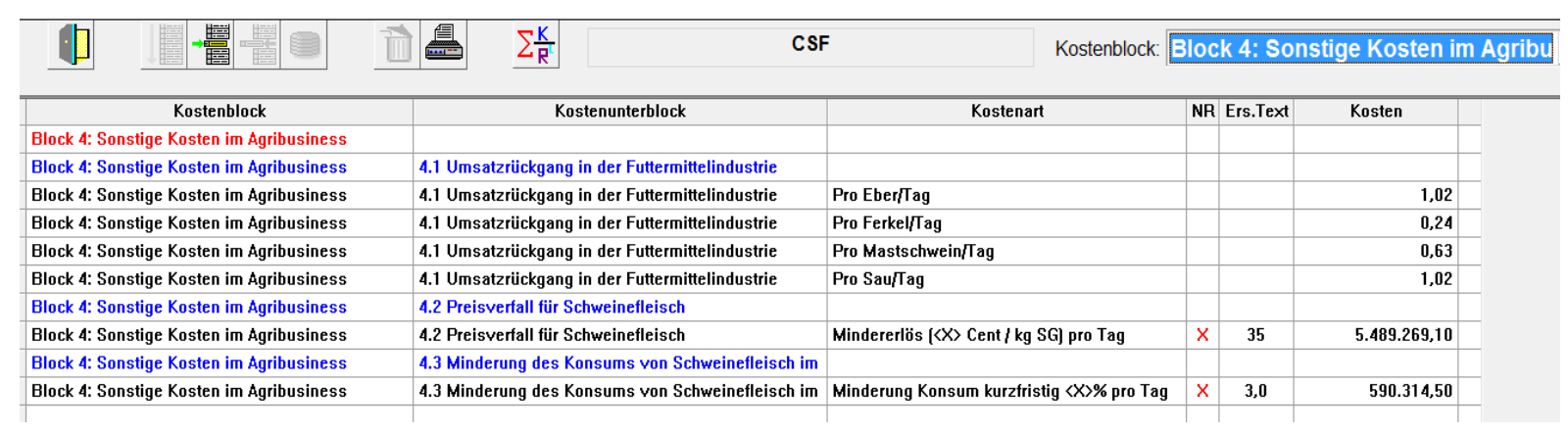

Figure 3. The representation of the cost category 4 in TEUS

Figure 4 shows the relations of an epidemic outbreak:

- $\quad$ push bottoms for the cost categories, percentage distribution and the calculation

- table of the animal density, distance, and time between the outbreak

table of the protection and surveillance zones with the radius, the respective strategies, and movement bans after an outbreak

- table of other parameters within a period of days 


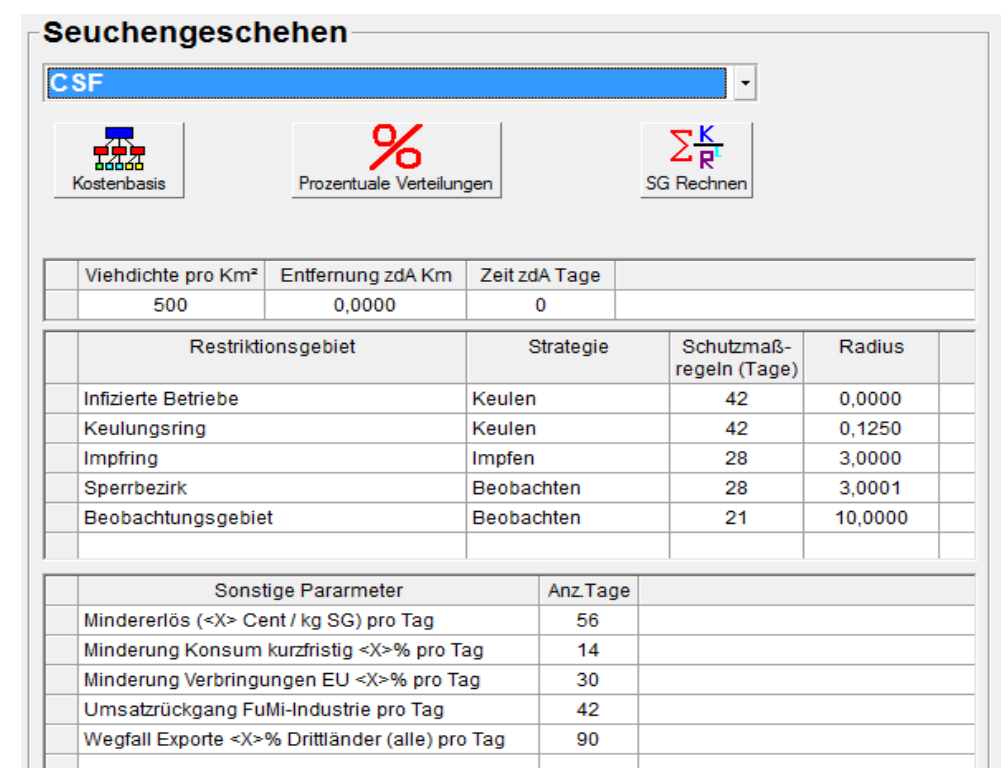

Figure 4. The representation of the relations of an epidemic outbreak

Figure 5 defines the possible variations of the parameters of an epidemic outbreak. This mask uses the three tables of Figure 4 expanded by the options to varying the parameters in their values, therefore making it possible to calculate a large number of scenarios.

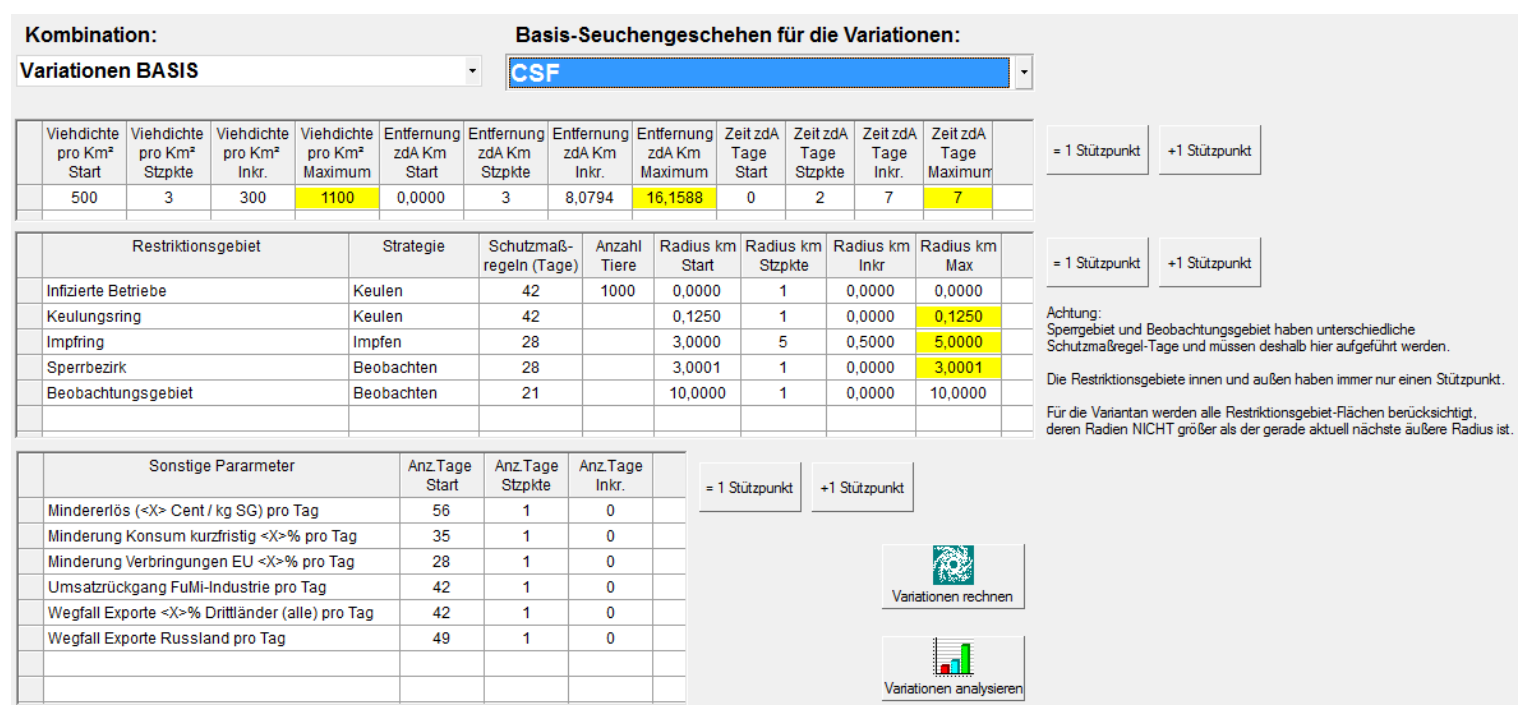

Figure 5. The variations of an epidemic outbreak

\section{Conclusions}

Despite observing due diligence regarding biosafety standards, epidemics of any kind can break out among animals at any time and any place. This is facilitated partly by liberal market policies, which also put nations in jeopardy of being infected with disease agents from far abroad. There is no way to be completely protected from this risk. A good example is the outbreak of highly pathogenic avian influenza (HPAI) at the beginning of 2015 in Germany, the Netherlands and Great Britain. It is unclear how the virus was able to take hold on farms that were geographically far apart and had differing housing systems. To date no relationships or interactions have been found between the affected farms (FLI, 2015).

In this paper we presented a complex relational database management system to economically assess an animal disease outbreak. Therefore, we addressed the assumptions for the calculation and introduced

doi: 10.17700/iai.2015.6.4.211

Maria Näther, Ludwig Theuvsen: Economic evaluation of animal disease control strategies: Application of a relational 
five cost categories and the parameters which have influence on the costs. Furthermore, we described important basics of TEUS, such as the ER-model or the respective algorithms. The programmed relational database system TEUS can generate and calculate different scenarios by varying parameters and thereby provide a decision space. Because economic effects of animal diseases have been more or less ignored until now, this paper can provide a new instrument to fill this research gap. The current animal disease control uses mainly tools which only concentrate for instance on geography, trade control, or information flows connected with livestock management and geo-references positions (Kroschewski et al. 2006). In light of the potential total calculated damages which TEUS currently foresees for Germany in case of a CSF or ASF outbreak, all European governments, livestock owners, the pork production industries (up- and downstream) and other stakeholders would do well to consider various scenarios of a swine fever outbreak to prepare and protect themselves accordingly.

Future research is especially needed to validate types of costs for specific countries and therefore expand with future scenarios of other European countries. For this, TEUS could likewise be used to determine and illustrate their economic impact. Therefore, TEUS is a unique instrument which enables the quick step-by-step building of a decision space (resulting set of variations by parameters) and the economic assessment of the available options in the case of a swine fever outbreak. Finally, via TEUS, it is possible to illustrate and economically evaluate further animal diseases in any country besides the examined cases of swine fever (ASF / CSF).

\section{Acknowledgements}

We wish to thank QS Wissenschaftsfonds for its financial support of this project.

\section{References}

Backer, J. A., Hagenaars, T. J., Van Roermund, H. J. W., \& De Jong, M. C. M. (2009) 'Modelling the effectiveness and risks of vaccination strategies to control classical swine fever epidemics'. Journal of the Royal Society, Interface / the Royal Society, 6(39), 849-61. doi: 10.1098/rsif.2008.0408

Bidder, A. (2006) Vogelgrippe - Der Feldzug des H5NI-Virus [Online]. Available: www.focus.de/gesundheit/ratgeber/vogelgrippe/chronik/2006/vogelgrippe_aid_26624.html, [Accessed: 23 Oct. 2013].

Blome, S. and Beer, M. (2013) Afrikanische Schweinepest: Eine hochgefährliche Tierseuche auf dem Vormarsch, Friedrich-Loeffler-Institut ForschungsReport 2/2013, Greifswald.

Blome, S. (2014) Personal Communication. 16. Dez. 2014.

Boklund, A, Toft, N., Alban, L., and Uttenthal, A. (2009) 'Comparing the epidemiological and economic effects of control strategies against classical swine fever in Denmark'. Preventive veterinary medicine 90(3-4): 180-193. doi: 10.1016/j.prevetmed.2009.04.008.

Brosig, J., Traulsen, I., and Krieter, J. (2012) 'Control of Classical Swine Fever Epidemics Under Varying Conditions - With Special Focus on Emergency Vaccination and Rapid PCR Testing'. Transboundary and Emerging Diseases 61(3): 258-65. doi: 10.1111/tbed.12028.

Council Directive 2001/89/EC. Community Measures for the Control of Classical Swine Fever. 23 October 2001, Brussels.

Deblitz, C. (2001): BSE und MKS in Europa und die Folgen für Argentinien, Braunschweig, p. 17.

Dieckhoff, H.J. (2014). Personal Communication. 17. December 2014.

Dürr, S., Zu Dohna, H., Di Labio, E., Carpenter, T. E., and Doherr, M. G. (2013) 'Evaluation of control and surveillance strategies for classical swine fever using a simulation model'. Preventive veterinary medicine 108(1): 73-84. doi: 10.1016/j.prevetmed.2012.07.006.

EMA (European Medicines Agency) (2014) 'Suvaxyn CSF Marker' [Online]. Available: www.ema.europa.eu/docs/en_GB/document_library/Summary_of_opinion_-_Initial_authorisation/veterinary/ 002757/WC500178951.pdf [Accessed: 14 Dec. 2014].

FLI (Friedrich-Löffler-Institut) (2015) Klassische Geflügelpest [Online]. Available: www.fli.bund.de/de/startseite/aktuelles/tierseuchengeschehen/klassische-gefluegelpest.html, [Accessed: 13 Feb. 2015]. 
Groeneveld, A. (2014). Personal Communication. 10 June 2014.

Hirsch, B. (2010) Effizientes Management von Tierseuchen. Hamburg.

Hop, G.E., Mourits, M.C.M., Oude Lansink, A.G.J.M. and Saatkamp, H.W. (in print). Cross-border collaboration in the field of highly contagious livestock diseases: a general framework for policy support. Transboundary and Emerging Diseases.

Jaeger, F. (2006) 'Bekämpfungsmanagement, Maßnahmen aus Sicht des Landes'. Paper presented at ZDS symposium on "Eckpunkte zur Schweinepest-Bekämpfung", Münster, 12 December 2006.

Kroschewski, K., Kramer, M., Micklich, A., Staubach, C., Carmanns, R. and Conraths, F.J. (2006) ,Animal disease outbreak control: the use of crisis management tools',Scientific and Technical Review of the Office International des Epizooties, 25: 211-221.

LWW-L (2014) 'Die Pest vor der Tür', Landwirtschaftliches Wochenblatt Westfalen-Lippe, Münster, 6 February 2014, p. 14.

Meuwissen, M.P.M., Horst, S.H., Huirne, R.B.M. und Dijkhuizen, A.A. (1999) 'A model to estimate the financial consequences of classical swine fever outbreaks: principles and outcomes', Preventive Veterinary Medicine, 42: 249-270. doi: 10.1016/s0167-5877(99)00079-3

Moennig, V. (2000) 'Introduction to classical swine fever: Virus, disease and control policy', Veterinary Microbiology, 73: 93-102. doi: 10.1016/s0378-1135(00)00137-1

Näther, M., Kayser, M., Lubig, J., and Theuvsen, L. (2013) 'Eine ökonomische Bewertung alternativer Tierseuchen-Bekämpfungsstrategien - am Beispiel der klassischen Schweinepest', Schriften der Gesellschaft für Wirtschafts- und Sozialwissenschaften des Landbaues e.V., vol. 49, pp. 247-258.

Ribbens, S., Goris, N., Neyts, J., and Dewulf, J. (2012) 'Classical swine fever outbreak containment using antiviral supplementation: a potential alternative to emergency vaccination and stamping-out'. Preventive veterinary medicine, 106(1): 34-41. doi: 10.1016/j.prevetmed.2012.03.002.

Statistisches Bundesamt (14. Juli 2011) Land- und Forstwirtschaft, Fischerei Viehbestand und tierische Erzeugung 2010 Fachserie 3 Reihe 4 [Online]: www.destatis.de/DE/Publikationen/ Thematisch/LandForstwirtschaft/ViehbestandTierischeErzeugung/ViehbestandtierischeErzeugung20304001070 04.pdf?_blob=publicationFile; [Accessed: 1 Nov. 2014].

SUS (Schweinezucht und Schweinemast) (2014) 'Angst vor Afrikanischer Schweinepest' [Online]. Available: www.susonline.de/Angst-vor-Afrikanische-Schweinepest-ASP-1361884.html, [Accessed: 05 Jan. 2014].

Thulke, H.H. (2014). Personal Communication. 11 December 2014. 